\title{
VULNERABILIDADE SOCIAL E ATENDIMENTO EDUCACIONAL ESPECIALIZADO: um olhar para práticas de governamentalidade
}

\author{
Liziane da Silva Barbosa \\ Universidade do Estado do Rio Grande do Sul - UERGS \\ Helena Venites Sardagna \\ Universidade do Estado do Rio Grande do Sul - UERGS
}

\begin{abstract}
Resumo
Este artigo trata de um estudo realizado no âmbito do curso de Especialização em Atendimento Educacional Especializado (AEE), na Universidade Estadual do Rio Grande do Sul. O objetivo é evidenciar as implicações da vulnerabilidade social produzidas no AEE enquanto lócus privilegiado das políticas inclusivas, no contexto biopolítico. Com base no campo conceitual da biopolítica e da governamentalidade, em Foucault, o estudo operou com esses conceitos como ferramentas analíticas. Utilizou entrevista com professores de espaço pedagógico denominado Sala de Recursos Multifuncional, em duas escolas públicas de um município do Litoral Norte do RS, uma da rede pública municipal e outra da rede pública estadual. Foi entrevistado ainda um representante da gestão dos espaços de oferta do AEE das escolas públicas estaduais. O exercício analítico possibilitou a organização dos dizeres em eixos temáticos: Zonas de Vulnerabilidade: Práticas de Governamento, apontando quais zonas de vulnerabilidade foram evidenciadas no contexto pesquisado; O AEE como Acionador de Engrenagens da Biopolítica, que problematiza as ações do professor do AEE como articulador das redes de apoio; e A Vulnerabilidade como Limite para $O A E E$, que torna evidentes os limitadores produzidos pela vulnerabilidade.
\end{abstract}

Palavras-chave: Vulnerabilidade Social. Governamentalidade. Biopolítica. Atendimento Educacional Especializado.

\begin{abstract}
This article deals with a study carried out within the scope of Specialization in Special Educational Service Course (SES) sphere, especially in including Special education's area, at State University from Rio Grande do Sul. The objective is to highlight the implications of social vulnerability produced in SES as a privileged locus of inclusive policies in the biopolitical context. Based on the conceptual field of biopolitics and governmentality, in Foucault, the study operated with these concepts as analytical tools. The research used an interview with teachers of pedagogical space called the Multifunctional Resource Room in two public schools of a municipality in the Northern Coast of Rio Grande do Sul, one of the municipal public network and another of the state public network. It was also interviewed a representative of the management of the spaces of offer of the SES of the state public schools. Such analytical exercise allowed the saying thematic axes's organization, which are: Vulnerability Zones: Governing Practices, pointing of which vulnerability zones were evidenced in this context. SES as an instruments starter's Biopolitics that will criticize the teacher's actions from SES as support web's articulator; and Vulnerability as limit to the SES that becomes evident the limiting produced by the vulnerability.
\end{abstract}

Keywords: Social Vulnerability. Governmentality. Biopolitics. Special Educational Service. 


\section{Considerações iniciais}

O presente artigo foi motivado por debates acadêmicos, de onde emergiram problematizações ainda não evidenciadas acerca das práticas articuladas com a educação inclusiva e 0 atendimento aos estudantes com deficiência, principalmente, quanto ao funcionamento e atuação do AEE nos processos de escolarização das crianças com deficiência. Dentre estas, a vulnerabilidade social e as situações de risco das crianças atendidas em instituições escolares, frequentemente, relatada pelos profissionais da educação.

Essa temática e problematização partem de experiências vividas como docentes de escola pública, onde a vulnerabilidade social é, muitas vezes, o motivo da não inclusão. É também uma temática, muito latente, que permeia discussões acerca dos processos de escolarização em todos os níveis e etapas da educação e que se evidenciou, também, entre os professores que atuam no AEE. Diante de tais relatos passaremos a tratar como zonas de vulnerabilidade, essas condições, uma vez que como afirma Castel, trata-se de:

[...] um espaço social de instabilidade, de turbulências, povoado de indivíduos em situação precária na sua relação com o trabalho e frágeis em sua inserção relacional. Daí o risco de caírem na última zona, que aparece, assim, como o fim de um percurso. É a vulnerabilidade que alimenta a grande marginalidade ou a desfiliação (CASTEL, p. 27, 1997).

Considerando isso, surgem questionamentos que compõem a problematização dessa pesquisa, como: examinar os efeitos da vulnerabilidade social nos processos de escolarização de crianças com deficiência atendidas nas Salas de Recursos Multifuncionais, bem como na atuação do AEE; como os profissionais do AEE entendem e identificam as zonas de vulnerabilidade social; que ações das zonas de vulnerabilidade social podem ser evidenciadas no desenvolvimento do AEE; e, que implicações a vulnerabilidade pode ter nos processos de escolarização das crianças atendidas no AEE.

O estudo busca sustentação teórico-metodológica nos estudos foucaultianos, compreendendo que os conceitos são ferramentas possíveis de operar com os dados, uma vez que não há uma teoria que expresse a prática, pois a teoria é uma prática (FOUCAULT, 2009a). Nesse sentido, o estudo proposto não delimitou categorias a priori, mas estas emergiram do exercício investigativo.

Enfatiza-se para o processo analítico, a noção de biopolítica como imperativo ${ }^{1}$ de Estado, na contemporaneidade, que aciona dispositivos de poder sobre a população, no sentido de controlar a probabilidade dos eventos, o equilíbrio entre individual e global e a segurança da população (FOUCAULT, 2008). As políticas inclusivas estão associadas ao campo biopolítico, ao regulamentar as condutas da população. Evidencia-se também a noção de governamentalidade como um conjunto de táticas, procedimentos e instituições que permite o exercício de poder sobre as massas, por meio de dispositivos de segurança (FOUCAULT, 2008). 
Essa problematização permitiu o uso da noção de “zonas de vulnerabilidade”, para discutir as vulnerabilidades e as situações de risco das crianças atendidas em instituições escolares, especificamente no âmbito da Educação Especial. Aproximamos essa noção às condições afirmadas por Castel, que denotam “[...] um espaço social de instabilidade, de turbulências, povoado de indivíduos em situação precária na sua relação com o trabalho e frágeis em sua inserção relacional. [...] É a vulnerabilidade que alimenta a grande marginalidade ou a desfiliação” (CASTEL, p. 27, 1997).

Nessa perspectiva, a intenção aqui é discutir acerca das implicações da vulnerabilidade social no Atendimento Educacional Especializado, na escola contemporânea, enquanto lócus privilegiado das políticas inclusivas, no contexto biopolítico, e como essas implicações se situam nas práticas de governamentalidade, que sancionam e regulam os processos. O estudo analisa práticas que, nas relações de poder, emergem em determinado tempo/espaço, com intencionalidades reguladoras e regulamentadoras da população. Para tanto, a pesquisa teve foco em espaços de oferta do AEE denominados Salas de Recursos Multifuncionais (SRM), de um município do Litoral Norte do Rio Grande do Sul/Brasil, em duas escolas da rede pública de ensino. A proposta inicial foi convidar um professor de cada uma das Salas das respectivas redes públicas de Cidreira e uma pessoa que reponde pela coordenação dessas salas. Atenderam ao convite e participaram os dois professores de SRM da rede pública municipal de Cidreira e um professor coordenador da educação inclusiva da rede pública estadual, que atua na Coordenadoria Regional de Educação ${ }^{2}$ do município de Osório, totalizando três professores entrevistados ${ }^{3}$. A metodologia de busca e análise de dados seguiu um roteiro de verificação de recorrências nas falas dos participantes e nelas evidenciar possíveis implicações da vulnerabilidade no processo inclusivo.

O exercício analítico possibilitou a discussão em torno de eixos que se interligam no desenrolar da temática: Educação Especial e Atendimento Educacional Especializado na Invenção Histórica traz um recorte da história da Educação Especial no Brasil e no mundo; Governamentalidade e Biopolítica como Ferramentas Analíticas apresenta ferramentas conceituais e metodológicas e descreve o caminho utilizado para a coleta e análise dos dados; O Uso das Ferramentas Conceituais nos Percursos Analíticos traz os dados analisados, a partir do campo conceitual da biopolítica em Foucault, nos processos de escolarização dos sujeitos que frequentam o AEE, e a relação desses processos com as práticas de governamentalidade.

\section{Educação especial e atendimento educacional especializado na invenção histórica}

A obra, Os Anormais de Michel Foucault, registra que o sujeito anormal é uma invenção da modernidade, num contexto histórico em que a anormalidade foi entendida como problema. Daí a emergência das três figuras, do século XIX, que são invenção de toda uma gama de instituições que classificam as degenerações - o monstro, o incorrigível e o onanista (FOUCAULT, 2003). Essas figuras não surgem de forma sincrônica na 
história, mas passam a se constituir a partir dos saberes jurídicos que determinam os sujeitos de direito, e dos saberes médicos que determinam a naturalidade biológica. Assim, as figuras que constituem o anormal são determinadas por saberes jurídico-biológicos (FOUCAULT, 2003).

A passagem dos tempos foi configurando a realidade atual, baseada em necessidades capitalistas. Nesse contexto, a lógica de reclusão e confinamento que imperava passa a figurar numa lógica de inclusão. Conforme podemos notar:

A Idade Clássica inventou-se técnicas de poder tais que o poder não age por arrecadação, mas por produção e maximização da produção. Um poder que não age por exclusão, mas sim por inclusão densa e analítica dos elementos. Um poder que não age pela separação em grandes massas confusas, mas por distribuição de acordo com individualidades diferenciais. Um poder que não é ligado ao desconhecimento, mas, ao contrário, a toda uma série de mecanismos que asseguram a formação, o investimento, a acumulação, o crescimento do saber. (FOUCAULT, 2003, p. 60)

Essa forma de poder mudou a relação com os indivíduos, de forma que não se sentissem amedrontados, mas sim acolhidos e trabalhando por um bem maior. Diferentemente do modelo medieval, o poder positivo ${ }^{4}$ buscava incluir todos os indivíduos, e não mais excluí-los. Diante dessa mudança, foi necessário construir mecanismos de classificação dos indivíduos - uma norma em que todos pudessem se reconhecer e que lutassem para mantê-la. "A norma não define uma lei natural, mas pelo papel de exigência e de coerção que ela é capaz de exercer em relação aos domínios a que se aplica, por conseguinte, a norma é portadora de uma pretensão ao poder” (FOUCAULT, 2003, p. 62).

Nesse momento histórico, todos os indivíduos tinham seu lugar marcado na sociedade, e aqueles que por “desventura” não estivessem dentro do padrão eram considerados anormais. Para conceituar a anormalidade e as anomalias, recorremos a Canguilhem (2002), na obra O Normal e O Patológico, que fez registros importantes para compreendermos os movimentos da Educação Especial, bem como o seu surgimento. Segundo ele:

É pela anomalia que o ser humano se destaca do todo formado pelos homens e pela vida. É ela que nos revela o sentido de uma maneira de ser inteiramente 'singular', e o faz primitivamente, de um modo muito radical e impressionante. Essa circunstância explica por que o 'ser doente' não esgota absolutamente o fenômeno da alienação que, impondo-se a nós sob o ângulo de 'ser de modo diferente' no sentido qualitativo da palavra, abre imediatamente caminho para considerações psicopatológicas feitas sob esse ângulo. (CANGUILHEM, 2002, p. 45)

Nesse sentido, o autor refuta a normalidade, pois afirma que a regularidade é inconstante. Trata-se de uma temática um tanto confusa e subjetiva, pois aborda os fatores conceituais que definem a deficiência e os sujeitos com deficiência, bem como o 
entendimento dos normais, frente à convivência com os deficientes. Esse entrelaçamento remete a uma alteridade, a uma construção da identidade (ou não identidade) dos indivíduos. Skliar (2003) afirma:

A alteridade deficiente, anormal, com significado que parece referir-se a um outro, só tem sentido se foge e refoge desse outro e se confronta a normalidade; o que faz falta é perder-se e perder-nos de vista, toda vez que o único é visto é a egocêntrica normalidade. Egocêntrica normalidade cuja infame tentação é a invenção do anormal. (SKLIAR, 2003, p. 154)

Nota-se, portanto, que a Educação Especial surge em contextos históricos diversos e que demandam um enquadramento no padrão da norma vigente, em relação às pessoas com deficiência. O processo de normalização social, política e técnica da sociedade, que se desenvolveu no século XVIII, manifestou seus efeitos no domínio de diversas áreas e instituições — na educação, surgiram as escolas normais; na medicina, a organização hospitalar e a divisão por área médica: doenças do corpo e da mente - e também no domínio da produção industrial. A norma era utilizada como poder: não apenas uma lei natural, mas um poder político. Trazendo consigo princípios de qualificação e de correção, não pretende excluir, nem rejeitar, e sim intervir - por meio de uma técnica positiva de transformação, uma espécie de poder normativo. Dessa forma, Foucault evidencia como os mecanismos e dispositivos normalizadores e de controle surgem pela necessidade de se pensar uma defesa social para os indivíduos anormais na sociedade. A instituição serviria como controle, como segurança.

É nesse panorama que se constitui o anormal e o sujeito que precisa ser corrigido, bem como as instituições de correção e de normalização. Outras teorias se entrelaçam no processo histórico, e surgem outros entendimentos, como o de Skliar (1997), que lança olhares sobre a diferença, alteridade e identidade e aponta para a forma como o outro foi persuadido para deixar de ser o outro. "Manipulado em cada um de seus detalhes para ir atrás da mesmidade. O outro foi naturalizado como anormal. E a normalização foi naturalizada” (SKLIAR, 1997, p. 178).

Todos os mecanismos de proteção aos direitos humanos e à educação como direito de todos se voltam para construir políticas e dispositivos que garantam a inclusão das pessoas com deficiência na sociedade. O governo neoliberal pressupõe que as necessidades do capitalismo, que depende da produção e da mão de obra, contribuem para essa universalização dos diretos, e as tecnologias também se colocam a serviço das pessoas com deficiência, a fim de garantir o máximo de acesso, com esforço mínimo do Estado.

\subsection{Governamentalidade e biopolítica como ferramentas de análise}

O termo governamentalidade, cunhado por Foucault, é usado para evidenciar práticas e políticas que conduzem os sujeitos de uma população, segundo Fimyar: 
Ao fundir o governar (gouverner) e a mentalidade (mentalité) no neologismo governamentalidade, Foucault enfatiza a interdependência entre o exercício do governamento (práticas) e as mentalidades que sustentam tais práticas. Em outras palavras, a governamentalidade pode ser descrita como o esforço de criar sujeitos governáveis através de várias técnicas desenvolvidas de controle, normalização e moldagem das condutas das pessoas. (FIMYAR, 2009, p. 38)

Outrossim, essas mentalidades referidas no excerto se constituem nas políticas e normativas que asseguram a efetivação do processo de governamento. Acerca da governamentalidade, Foucault afirmou que se trata de:

1 - o conjunto constituído pelas instituições, procedimentos, análises e reflexões, cálculos e táticas que permitem exercer esta forma bastante específica e complexa de poder, que tem por alvo a população, por forma principal de saber a economia política e por instrumentos técnicos essenciais os dispositivos de segurança.

2 - a tendência que em todo o Ocidente conduziu incessantemente, durante muito tempo, à preeminência deste tipo de poder, que se pode chamar de governo, sobre todos os outros - soberania, disciplina, etc. - e levou ao desenvolvimento de uma série de aparelhos específicos de governo e de um conjunto de saberes.

3 - resultado do processo através do qual o Estado de justiça da Idade Média, que se tornou nos séculos XV e XVI Estado administrativo, foi pouco a pouco governamentalizado. (FOUCAULT, 2009, p. 291-292)

O exercício da presente pesquisa considera especialmente o primeiro item para olhar para os dados, que dá relevo às formas de poder sobre a população, à ação do biopoder e às formas de poder sobre o indivíduo (poder disciplinar), ao mesmo tempo. Esses movimentos estão configurados e organizados em um sistema que Foucault (2008) definiu como biopolítica. A biopolítica também trata de todo o conjunto de estratégias, táticas, mecanismos e dispositivos que fundamentam e sustentam a governamentalidade para a população. Cabe destacar que a governamentalização do Estado permitiu o desenvolvimento da biopolítica; dessa forma, administra-se o Estado gerindo a população, isto é, o Estado não age diretamente na população: o próprio conjunto de indivíduos exerce atividade de autocontrole. Segundo o mesmo autor, “o fato de viver não é mais esse sustentáculo inacessível que só emerge de tempos em tempos, no acaso da morte e de sua fatalidade: cai, em parte, no campo de controle do saber e de intervenção do poder” (FOUCAULT, 1988, p. 134).

É nesse sentido que a biopolítica opera, para manter e garantir a vida. E para a manutenção da vida e do poder sobre ela, criam-se mecanismos de governamento no contexto da biopolítica - tudo isso guiado pelos rumos de mercado e da produtividade dos sujeitos. Não mais se usa a força e a repressão, mas sim o convencimento, com economia política. Dessa forma, o esforço para o governamento é mínimo, pois quem é convencido e 
se governa para atender as diretrizes de manutenção à vida também passa a governar (FOUCAULT, 2008). A ação da biopolítica na vida humana está assim colocada:

Se pudéssemos chamar de 'bio-história' as pressões por meio das quais os movimentos da vida e os processos da história interferem entre si, deveríamos falar de 'biopolítica' para designar o que faz com que a vida e seus mecanismos entrem no domínio dos cálculos explícitos, e faz do poder-saber um agente de transformação da vida humana. (FOUCAULT, 1988, p. 134)

Sob essas, lentes é possível olhar para os processos da vulnerabilidade social como um fator de implicação no Atendimento Educacional Especializado, enquanto práticas de governamento na biopolítica. Cabe destacar que "não é a atividade do conhecimento que produziria um saber, útil ou arredio ao poder, mas o poder-saber, os processos e as lutas que o atravessam e o constituem, que determinam as formas e os campos possíveis do conhecimento" (FOUCAULT, 1979, p. 31).

No movimento da efetivação da inclusão e da implantação de Salas de Recursos para o AEE, o jogo de poder-saber está sempre em processo de construção e desconstrução, entre lutas e processos de escolarização, que não somente produzem sujeitos, mas diversos saberes, os quais constituirão novas práticas. Nesse sentido, entender a governamentalidade precede a compreensão de "quais técnicas discursivas estão envolvidas com a criação da realidade e como são estabelecidas as operações modernas de poder-saber” (FIMYAR, 2009, p. 52). Essas operações interessam para o campo acadêmico também para produzir sujeitos com “mentalidades” inclusivas e saberes que operem novas práticas de condução de condutas, para que a inclusão das pessoas com deficiência se concretize na gênese dos processos de escolarização.

As políticas públicas para a Educação Especial são práticas normalizadoras e condutoras das condutas dos sujeitos. Segundo Foucault (2008), a governamentalidade trata de uma série de "técnicas e procedimentos destinados a dirigir a conduta dos homens. Governo das crianças, governo das almas ou das consciências, governo de uma casa, de um Estado ou de si mesmo” (FOUCAULT, 1979, p. 101). Assim, a governamentalidade tornase uma ferramenta conceitual de análise das práticas vistas no campo de pesquisa, pois:

A analítica da governamentalidade examina as práticas de governamento em suas complexas relações com as várias formas pelas quais a verdade é produzida nas esferas social, cultural e política. Portanto, o papel da analítica de governamento é o de diagnóstico; o que Rose chama de "procurar uma relação crítica franca às estratégias de governamento, com atenção a suas pressuposições, suas suposições, suas exclusões, suas ingenuidades, suas velhacarias, seus regimes de visão e seus pontos de cegueira” (ROSE, 1999, p. 19 apud FIMYAR, 2009, p. 37)

A discussão dá prerrogativa exatamente para esses pontos sobre os quais a biopolítica ainda não está agindo ou não está obtendo sucesso. Cabe destacar que a biopolítica aqui 
referenciada é a mesma que Foucault registrou, e que se refere a uma mudança de regime, quando a soberania dá lugar ao biopoder, "poder de 'fazer' viver e de 'deixar' morrer [...]” (FOUCAULT, 2002, p. 287). Buscou-se evidenciar essas políticas e práticas de governamento, além de perceber onde elas não estão agindo em favor das vidas e das populações, bem como onde as zonas de vulnerabilidade social estão inseridas nas estratégias de governamento para a Educação Especial e o AEE.

O estudo inspirou-se em princípios da genealogia em Foucault, que busca fragmentos históricos para compreender, no passado, a marca e as condições de emergência das práticas de governamento relacionadas à inclusão, questionando as possibilidades desses acontecimentos nos dias de hoje. A genealogia faz referência aos estudos de Foucault, em que ele analisa as formas de exercício do poder com as suas aparições na história. Ela ativa os diversos saberes que emergem e produzem os sentidos, a partir das condições de possibilidades externas aos próprios saberes. "É a tática que, a partir da discursividade local assim descrita, ativa os saberes cobertos da sujeição que emergem desta discursividade” (FOUCAULT, 2009b, p. 172). Utilizando essa ferramenta, procura-se "a explicação dos fatores que interferem na sua emergência, permanência e adequação ao campo discursivo, defendendo sua existência como elementos incluídos em um dispositivo político” (FAÉ, 2004, p. 413).

Essas interlocuções nos permitem compreender e mostrar para os leitores quais sentidos e conceitos foram produzidos, de forma a conceber as zonas de vulnerabilidade e onde elas se entrelaçam com as políticas de inclusão, especialmente no AEE das escolas públicas em questão.

A análise buscou registros oficiais, como o Atlas da Vulnerabilidade Social nos Municípios Brasileiros, publicado em 2015, que não só trata dos conceitos produzidos para a vulnerabilidade social, como também aponta diagnósticos das zonas de risco social em todo o Brasil. Utilizou-se também uma publicação realizada em 2007, do Ministério do Trabalho, intitulada Aspectos Conceituais da Vulnerabilidade Social, que trata dos movimentos mundiais que regeram as mudanças conceituais do que se entende por vulnerabilidade social, mais especificamente no mundo do trabalho. Buscamos a perspectiva das zonas de vulnerabilidade social no Estatuto da Pessoa com Deficiência, promulgado em 2015, no qual está regulamentada e consolidada a legislação que ampara a pessoa com deficiência em todos os espaços da sociedade, incluindo as instituições escolares.

Em todos os textos, parece não haver entrelaçamento entre vulnerabilidade e deficiência - cada texto trata das temáticas isoladamente. Em vários aspectos, a vulnerabilidade é compreendida ou inventada como um indicador de acesso a políticas públicas e ferramentas sociais. Nesse sentido, esse indicador é medido a partir da lógica da participação de programas sociais, situação que apresentou uma elevação significativa entre os anos de 2000 e 2010 (ATLAS, 2015). Segundo consta neste documento:

A análise integrada do desenvolvimento humano com a vulnerabilidade social oferece o que se denomina aqui de prosperidade social. A prosperidade social é 
a ocorrência simultânea do alto desenvolvimento humano com a baixa vulnerabilidade social, sugerindo que, nas porções do território onde ela se verifica, ocorre uma trajetória de desenvolvimento humano menos vulnerável e socialmente mais próspera. (ATLAS, 2015, p. 74)

Cria-se, dessa forma, uma noção de que o acesso aos programas sociais é fator de prosperidade e, assim, os indicadores inventam ${ }^{5}$ novas perspectivas para as zonas de vulnerabilidade.

\section{O uso das ferramentas conceituais nos percursos analíticos}

O exercício permite evidenciar algumas práticas de condução das condutas dentro do contexto escolar, cujas articulações biopolíticas incidem sobre as zonas de vulnerabilidade social. Ainda que as práticas tencionem buscar os sujeitos vulneráveis para o jogo de consumo e para o jogo das políticas para a vida, relacionam-se às falhas nas redes estabelecidas na malha biopolítica e não conseguem resgatar os sujeitos com deficiência da condição de vulnerável.

\subsection{Interlocuções possíveis no campo empírico}

Os dados do campo empíricos advêm dos participantes que se dispuseram a conceder uma entrevista. Foram convidados dezesseis professores, porém, a entrevista foi realizada com aqueles que retornaram ao convite confirmando a participação. O critério para direcionar o convite foi a atuação no serviço de apoio do Atendimento Educacional Especializado, ofertado em Salas de Recursos Multifuncionais, bem como a atuação em órgão oficial da educação, responsável pela gestão da Educação Especial e inclusiva das Redes de Ensino municipal e estadual: a Coordenadoria Regional de Educação responsável pelas escolas públicas estaduais da região Litoral Norte e a Secretaria de Educação do município de Cidreira/RS.

Os participantes foram dois professores de Salas de Recursos Multifuncionais de escolas públicas (um professor de escola pública municipal e um professor de escola pública estadual) e um professor coordenador da educação inclusiva da rede estadual, totalizando três professores entrevistados ${ }^{6}$. Os sujeitos participantes foram escolhidos por atuarem em SRM ou se ocuparem do Atendimento Educacional Especializados, na rede pública de ensino. Os participantes serão identificados com nomes fictícios, a fim de proteger a sua identidade; as escolas em que trabalham não serão identificadas, conforme acordado com eles.

A participante da escola estadual, professora de SRM, será identificada como Anita e tem formação inicial em Pedagogia e Especialização em Deficiência Mental. Trabalha na área há cerca de um ano. A coordenadora estadual será identificada pelo nome de Eliana e tem formação inicial em Educação Física, além de algumas especializações na área da 
Educação Especial. Ela afirma que sua meta é "ter todas as formações de todas as deficiências que são público alvo da EE, cursos de 400h"” (ELIANA). Trabalhando na área desde 2016, começou como professora de classe especial e hoje atua como coordenadora do AEE da rede estadual do Litoral Norte do RS. O professor da rede municipal será identificado como Paulo e tem formação inicial em Pedagogia e Especialização em Educação Especial Inclusiva. Ele está atuando como educador especial há quatro anos. Os participantes foram entrevistados em separado e responderam livremente às perguntas do roteiro de entrevista, acrescido de algumas que foram feitas durante esse momento.

As entrevistas foram gravadas e posteriormente transcritas. Na sequência, as narrativas foram sendo descritas e tematizadas por recorrência, sendo gerado primeiro exercício, cujo material originou as análises. Os eixos analíticos foram organizados nesse exercício. Levou-se em conta que os dizeres dos participantes são acionados pelos discursos que vão constituindo significados na sociedade governamentalizada (FOUCAULT, 2004). Assim, os sujeitos são interpelados e por esses significados.

A seguir, apresentamos os eixos de análises, os quais evidenciam os achados da pesquisa.

\subsection{Zonas de vulnerabilidade: práticas de governamento}

A partir dos relatos dos participantes, bem como da análise dos dados complementares, foi possível perceber que existe correlação entre os sentidos atribuídos pelos participantes e os conceitos compostos pelas estatísticas nacionais, evidenciando aí a condução dos olhares dos professores para perceber ou enunciar as vulnerabilidades e torná-las fator alvo de políticas públicas neoliberais.

[...] certas normas são instituídas não só com a finalidade de posicionar os sujeitos dentro de uma rede de saberes, como também de criar e conservar o interesse em cada um em particular, para que se mantenha presente em redes sociais e de mercado. Todos estamos, de uma maneira sendo conduzidos por determinadas práticas e regras implícitas que nos levam a entrar e permanecer no jogo econômico do neoliberalismo. (LOPES, 2009, p. 155)

No contexto da rede municipal, as zonas de vulnerabilidades estão caracterizadas nos dizeres do professor, como:

um indicador compõe com várias variáveis, podemos citar algumas: renda familiar; condições de moradia; se tem cadastro na assistência social, para algum benefício; se participa, já, de algum programa assistencial do governo; $e$ tem vários outros, mas os principais seriam esses, que aí a gente já levanta a hipótese para buscar novas informações. (PAULO)

Esses apontamentos feitos pelo professor são os mesmos utilizados para dar sentido aos conceitos que inventam as vulnerabilidades, nos documentos oficiais. 
As noções de "exclusão" e de "vulnerabilidade social” têm sido cada vez mais utilizadas, no Brasil e no mundo, por pesquisadores, gestores e operadores de políticas sociais, num esforço de ampliação do entendimento das situações tradicionalmente definidas como de pobreza, buscando exprimir uma perspectiva ampliada complementar àquela atrelada à questão da insuficiência de renda. (ATLAS, 2015, p. 12)

Essa ampliação de entendimento busca motivar os sujeitos para o direcionamento da população que se encontra em zonas de vulnerabilidade social, como parte de uma estratégia de governamento de condutas, que procura resgatar os sujeitos com deficiência dessas zonas de vulnerabilidade. No contexto da rede estadual, a professora Anita afirma que é necessário "acionar o Conselho Tutelar para garantir que o aluno frequente o AEE, senão ele não vem, porque a família não consegue consulta médica para obter o laudo" (ANITA), demonstrando que, para que as zonas de vulnerabilidade não impeçam o sujeito de acessar o AEE, é necessário acionar a rede de ferramentas sociais e programas sociais que os mantêm motivados a permanecer no jogo.

Essa rede de saberes, notadamente, age como disparador do biopoder, no funcionamento da biopolítica, no sentido de que o sujeito professor precisa manter o sujeito com deficiência na estatística da inclusão. Dessa forma, trabalha para que este se mantenha em atendimento, direcionando-o aos mecanismos biopolíticos que o governam.

Contudo, no contexto da Educação Especial Inclusiva, o trabalho consiste em eliminar a exclusão do sujeito com deficiência e, para isso, articula políticas que oferecem as estratégias e os serviços para tal, incluindo o AEE. Diante disso, pode-se afirmar que o professor do AEE, ao se apropriar dos indicadores da vulnerabilidade e reconhecê-los no contexto escolar, evidencia onde as estratégias e táticas da biopolítica ainda não alcançaram a população. Desse modo, passa a ser agente das táticas biopolíticas, uma vez que reconhece as vulnerabilidades como limite para a efetivação da política pública de inclusão.

Nesse sentido, ao fazer uma analogia dos processos que colocam em funcionamento as políticas de elevação da vida, a exemplo das políticas inclusivas com o AEE, e da minimização da vulnerabilidade social, foi pertinente associar esse funcionamento a um amplo mecanismo, em que são necessários acionadores para movimentar engrenagens da biopolítica. Considerou-se que esses processos compõem o conjunto de dispositivos que controlam a probabilidade dos eventos, que movem estratégias de equilíbrio entre individual e global. Tais acionadores são colocados em movimento para a segurança da população.

\subsection{O AEE como acionador de engrenagens da biopolítica}

Os dados apontaram que o serviço de AEE dentro da escola se configura em uma potente engrenagem biopolítica, pois aciona as estratégias e táticas, para melhor funcionamento da governamentalidade. À medida que são detectadas situações de 
vulnerabilidade social entre os sujeitos com deficiência, são acionadas as redes de proteção social para efetivar o processo de escolarização e de inclusão.

Na rede estadual, existe um sistema no qual os estudantes com deficiência devem ser registrados, com o intuito de garantir o atendimento no serviço de AEE. O processo de inserção no sistema ocorria na seguinte forma:

os alunos eram encaminhados pelo professor da sala regular, aí a professora, com laudo ou sem laudo; o que tem laudo a mãe já chega na escola, a bem dizer, com a pastinha, quase doutora na deficiência do seu filho, nos dando todo o apoio possível, porque já vem de uma trajetória de antes da escola com aquela criança, nasceu assim [...]. (ELIANA)

A referência ao laudo médico deve-se à exigência deste para a inserção do sujeito com deficiência no processo de inclusão. “[...] o aluno só vai ser atendido, aqui na Sala de Recursos, se ele tiver um laudo, especificando a deficiência. Se o aluno não tiver nenhuma deficiência, ele não é atendido nessa Sala de Recursos” (ANITA). Ocorre que, segundo as participantes, para a obtenção desse laudo, a família do estudante precisará enfrentar uma extensa jornada pelos serviços básicos, quem nem sempre são acessíveis.

Na rede pública municipal, o processo ocorre de forma parecida. Segundo o professor, o aluno vem encaminhado de três formas:

[...] pelo terapeuta, aquele que já tem a família organizada, um atendimento contínuo. O terapeuta dá o laudo e o aluno já chega na matrícula com o encaminhamento para a Sala de Recursos; a segunda é aquele aluno que vem dar continuidade ao atendimento que já tinha em outro município [...]; e a terceira forma é aquele aluno que nós descobrimos o caso, ele vem com histórico de déficit de aprendizagem, baixo rendimento escolar, a gente chama os pais e encaminha para o atendimento clínico, e vai realizando os pareceres pedagógicos para contribuir na busca por um laudo, quando é o caso, e a orientação, direção e coordenação pedagógica conversam bastante nesse sentido, pra possibilitar o acesso à Sala de Recursos. (PAULO)

Esses trâmites exigem a articulação de uma série de serviços públicos essenciais, para o funcionamento do serviço de AEE na escola. Evidenciou-se a existência de um sistema interligado de serviços públicos, que tem por objetivo inserir os sujeitos com deficiência dentro do jogo social de produção e consumo. No entanto, para que a efetivação da inclusão seja possível, é necessário que esse sistema esteja em funcionamento desde a matrícula do estudante com deficiência, ou a partir do início da investigação sobre a deficiência do aluno.

Mais que isso, o poder de governar esses sujeitos depende dessas engrenagens. Então, é nesses movimentos de busca pela efetivação das políticas públicas que o AEE passa a ocupar uma posição de acionador das engrenagens da biopolítica. É por meio da ação do 
professor da SRM que as táticas, os mecanismos e dispositivos passam a ser efetivados. Um exemplo dessas práticas pode ser visto no relato do professor Paulo, que afirma:

[...] buscava muito a instalação e participação da rede, o $C A E^{8}$, a assistência social, a Casa da Mulher, o Conselho Tutelar e até em outros municípios [...], mas começou a haver muita resistência, então eu fui deixando de lado, pois o trabalho na sala e o atendimento aos professores estavam ficando de lado, sem a atenção necessária [...] Eu vejo que isso é muito importante, fundamental, mas sozinho não dá. (PAULO)

A ação do professor em procurar soluções para qualificar o atendimento se configura em uma forma de direcionamento, a fim de atender às demandas emergentes do jogo político neoliberal. Ao mesmo tempo em que cumpre tarefas das práticas de governamento, percebe que é necessária a articulação dos serviços de apoio; nesse sentido, conduzir outros comportamentos dentro do processo de escolarização remete a uma aproximação com as práticas discursivas que Foucault registrou: "em toda sociedade a produção do discurso é ao mesmo tempo controlada, selecionada, organizada e redistribuída por certo número de procedimentos que têm por função conjurar seus poderes e perigos” (FOUCAULT, 2004, p. 8-9).

A observação e o reconhecimento das falhas da rede de serviços sociais básicos podem ser compreendidos como a própria governamentalidade operando e conduzindo os sujeitos do AEE a acionarem as engrenagens da biopolítica, uma vez que "esta é a base do poder, a forma de saber/poder que vai dar lugar não às grandes ciências de observação, como no caso do inquérito, mas ao que chamamos ciências humanas: psiquiatria, psicologia, sociologia etc." (FOUCAULT, 1974, p. 70).

Nota-se que está em processo uma urgência no reconhecimento dessas zonas de vulnerabilidade, quando se condiciona o acesso ao serviço de AEE a laudos médicos e terapias complementares. Provoca a ação dos professores no sentido de fazer cumprir a exigência e faz com que eles acionem os demais serviços, que têm por objetivos também o controle da população, ou seja, “a escola, mais uma vez, é colocada como a melhor possibilidade de melhoria de vida, não só no campo intelectual e profissional, mas ela também vem revestida de uma responsabilidade cada vem mais investida do social” (SANTAIANA, 2008, p. 97).

Essa condição se manifesta no dizer do professor: "chega uma hora que o professor tem que escolher entre brigar pelos direitos que a criança tem ou dar o melhor atendimento possível para a criança e, pelo menos, na escola ela teria uma infância melhor, uma criança de verdade" (PAULO). Essa noção de que existe uma criança de verdade e, para além disso, o fato de o professor tomar para si a tarefa de brigar pelos direitos dessa criança, é também parte de um jogo político neoliberal. Esse jogo desafia o comprometimento do professor em relação à criança e produz uma ação em favor da efetivação de uma estratégia biopolítica, pois este foi seduzido a agir pela causa da educação inclusiva, e assim o fará, a qualquer custo. É possível perceber que “O problema não é o da mudança, da conscientização das pessoas, nem do que há em suas cabeças, mas 
do regime político, econômico e institucional da produção de verdades” (FOUCAULT, 1979, p. 47).

Essa produção de verdades tem influência direta na condução e no direcionamento das tarefas do AEE, já que o professor que atua nesse espaço precisa desempenhar um trabalho que está atrelado a outros setores sociais, os quais devem funcionar em favor da mesma verdade: incluir os sujeitos com deficiência e garantir-lhes o acesso ao jogo econômico.

O professor da rede pública municipal refere que "[...] a escola percebeu o baixo rendimento e começou a se envolver, a direção falou com alguns comerciantes para conseguir trabalho e aí com o dinheiro ele começou a construir sua própria casa e outro comerciante o ajudou com materiais, e a família começou a se reerguer" (PAULO). Já a coordenadora da rede pública estadual enfatiza que "[...] as professoras do AEE estão chegando ao ponto de [...] chamar a família, conseguir com o município uma van, colocar essas crianças, elas marcarem as consultas. A escola interferindo junto com a família, claro, pra marcar essas consultas e levar a família na consulta médica” (ELIANE).

Esses dois relatos evidenciam que os profissionais que atuam pela efetivação das políticas públicas de educação inclusiva, em nome desse compromisso, também acionam políticas de assistência social e exercem poder sobre os setores responsáveis, fazendo cumprir as metas de elevação social. No contexto pesquisado, "os professores apontam as crianças e a equipe diretiva e pedagógica tenta ir atrás do por que, e quando percebe que a família que não tem mesmo condições de se autossustentar, a escola tenta fazer esse papel de Assistente Social e até mesmo de exigir” (PAULO). Nesse movimento, evidenciase a produção de saberes que funcionam como condições de possibilidade para a criação e manutenção de ordens sociais.

Evidentemente, os professores e coordenadores do AEE, imbuídos do discurso que os seduziu, acionam engrenagens que possibilitam a operação da governamentalidade, ao assumirem para si papéis que, em um sistema político-democrático, são deveres do Estado.

\subsection{A vulnerabilidade como limite para o AEE}

Esse eixo emerge dos dados coletados, como o corolário da questão inicial desta pesquisa, pois evidencia que as implicações da vulnerabilidade social se configuram em limites para a efetivação do serviço de AEE. Essas implicações, entre os muitos relatos e dizeres dos sujeitos participantes, surgem como conjunturas que comprometem o desenvolvimento do trabalho e o assujeitamento dos alunos com deficiência, uma vez que estão inseridos em zonas distantes, nas quais o jogo de poder econômico de produção e consumo se exerce de forma diferente.

Aqui convém destacar que os participantes relataram não produzir documentos de registros socioeconômicos das crianças atendidas, e que todas as informações que possuem em relação a essa condição advêm da observação e das histórias contadas por professores de turmas anteriores. Nem mesmo registros pedagógicos dos atendimentos e das ausências são construídos, configurando um limite tanto para a efetivação do AEE, quanto para o acionamento das demais ferramentas sociais necessárias à continuidade dos atendimentos. 
Assim, é notável que as falhas na rede de serviços que viabilizam o acesso e a permanência dos sujeitos com deficiência na escola interrompem a ação da governamentalidade, uma vez que limitam a continuidade do serviço e a condução das condutas. Segundo a professora Eliana, da rede estadual: "[...] o professor do AEE tem que estar envolvido em todos os setores da escola, no pátio, na biblioteca, na merenda, ele tem que esclarecer às serventes como é que esse aluno funciona [...]”, deixando claro que o profissional do AEE precisa interagir com todos os setores da escola, a fim de orientar as condutas para com esse sujeito e dele para com os demais.

Contudo, a mesma professora relata que as escolas e equipes diretivas "estão com dificuldade de entender e operacionalizar esse trabalho" (ELIANA). Nesse ínterim, os fatores da vulnerabilidade, identificados por ela tornam-se limitadores desse processo, já que, dos 565 estudantes atendidos nas SRM, ela estima que a metade apresente aspectos compatíveis com as zonas de vulnerabilidade. A professora Anita também refere que a problemática da vulnerabilidade social interfere na sua atuação, pois enfrenta diversas situações em que "a mãe não quer levar, é difícil levar, ela não consegue consulta. Então assim, a partir dessa semana, nós vamos acionar o $C T^{9}$ para apoiar. Ou ela aceita ser atendida ou nós vamos registrar em ata também, que está desistindo do atendimento, e quais os motivos”. Essa nova orientação de que trata a professora - e à qual a coordenadora também refere - já se constitui em um assujeitamento das famílias, para que levem os seus filhos com deficiência ao sistema de saúde, de forma que este ateste a sua condição.

O Conselho Tutelar funciona como tática na busca por romper o limite que impede o aluno de acessar os serviços de apoio, como os da saúde. Entretanto, na contramão da normativa está a ineficiência da rede de serviços, pois, conforme o relato da coordenadora:

a gente tem que trabalhar em conjunto, todo mundo pra gente poder ajudar essa criança, porque [...], as dificuldades socioeconômicas podem trazer nos comprometimentos ou agravar os comprometimentos que essas crianças possam ter. [...], não temos ainda padrões, planilhas, estatísticas a esse respeito, mas que isso é visível, pra quem trabalha na área do AEE, é totalmente visível. (ELIANA)

Percebe-se, nesses relatos, que existe um movimento em cadeia, uma vez que, embora não sejam feitos registros que atestem os aspectos da vulnerabilidade, ela é visível, porque interrompe o ciclo das estratégias biopolíticas, resultando numa "quebra do trabalho do $A E E$ ” (ELIANA). Diante disso, Lopes se utiliza de conceitos foucaultianos para afirmar:

certas normas são instituídas não só com a finalidade de posicionar os sujeitos dentro de uma rede de saberes, como também de criar e conservar o interesse em cada um em particular, para que se mantenha presente em redes sociais e de mercado. Todos estamos, de uma maneira sendo conduzidos por determinadas práticas e regras implícitas que nos levam a entrar e permanecer no jogo econômico do neoliberalismo. (LOPES, 2009, p. 155) 
Na rede municipal, o professor identificou uma relação direta entre o histórico de vulnerabilidade social do sujeito com deficiência e o desenvolvimento do serviço do AEE. Ele afirma que "essa vulnerabilidade social leva à falta de estímulo, e a falta de estímulos limita o desenvolvimento" (PAULO). Além disso, o professor percebe que o acesso aos serviços de saúde e às terapias complementares ao AEE é apenas uma porta para que as famílias oriundas das zonas de vulnerabilidade recebam o "benefício do governo", e que, após essa obtenção, as famílias abandonam os acompanhamentos terapêuticos e os serviços do AEE. Nota-se que, nesses casos, já existem ferramentas da governamentalidade operando, pois essas famílias conhecem as estratégias da política de inclusão, para obter acesso aos auxílios financeiros que motivam a permanência do sujeito com deficiência na escola.

De acordo com Lopes, “Garantir para cada indivíduo uma condição econômica, escolar e de saúde pressupõe estar fazendo investimentos para que a situação presente de pobreza, de falta de educação básica e de ampla miserabilidade humana talvez se modifique em curto e médio prazo" (LOPES, 2009, p. 167).

Essas articulações colocam os sujeitos em uma malha biopolítica que, ao mesmo tempo em que lhe concede um direito, também lhe impõe um dever. Nesse caso específico, o auxílio para a pessoa com deficiência está condicionado aos cadastros da assistência social do município e à frequência escolar. Então, o sujeito cumpre a meta do Estado de incluir a todos e passa a fazer parte do jogo econômico (LOPES, 2009). Na contramão desses movimentos, estão aqueles que não conseguem acesso e pouco são capturados pelos dispositivos. São esses que preocupam os professores do AEE, uma vez que, quando a rede falha, o sujeito com deficiência perde o direito de acessar os mecanismos de inclusão, “porque as redes de apoio não estão consolidadas no município” (PAULO).

A partir do entendimento de que a governamentalidade depende do funcionamento das estratégias e dos dispositivos biopolíticos, pode-se depreender que, nos dados apresentados, estão também os limitadores que constituem a malha da biopolítica, e que impedem a efetivação plena das políticas e o cumprimento das metas do neoliberalismo. Não obstante, também fica evidente que as ações dos professores do AEE denotam que a emergência desses limites descritos é correlativa com o exercício da governamentalidade, pois, ao mesmo tempo em que comprometem as ações de inclusão dos sujeitos com deficiência, incidem em nova atribuição para os sujeitos que impulsionam as políticas do AEE.

\section{Considerações finais}

Na leitura e articulação dos dados com os conceitos da governamentalidade e da biopolítica, percebem-se os movimentos condutores das ações dos sujeitos envolvidos em favor de incluir os sujeitos com deficiência e, ao mesmo tempo, questionar a rede de serviços sobre as falhas que impossibilitam esse acesso. Em várias etapas da pesquisa, a 
vulnerabilidade era destacada como fator de falta de acesso às políticas públicas e às ferramentas sociais. Ao mesmo tempo em que os participantes demonstravam que estavam a serviço da educação inclusiva e possuíam os conhecimentos para exercer a função, deixavam claro que, ao exigir o funcionamento da rede, criavam pontos de ineficiência no serviço do AEE.

Os dados mostraram que a vulnerabilidade social se constitui, para o serviço do AEE, como um limite severo para a efetivação das políticas de inclusão na escola, mas também, por ser reconhecida em suas características de produção de sujeitos, impulsiona as ações dos sujeitos professores no sentido de acionar as engrenagens da biopolítica.

Esta pesquisa está também atendendo ao cumprimento de metas estabelecidas para a segurança e elevação da vida em uma perspectiva neoliberal. Façamos “a nossa parte”, evidenciando falhas nas engrenagens da biopolítica como parte de nosso assujeitamento às práticas de governamento, colocando-nos a serviço das engrenagens da biopolítica, cientes e conscientes de que esse movimento não trata de uma inovação pessoal, mas sim do resultado de um governamento que nos direciona a acionar engrenagens biopolíticas que garantam a inclusão das pessoas com deficiência.

A continuidade deste estudo reside na possibilidade de aprofundar a busca pela emergência dos sujeitos vulneráveis no contexto das políticas de inclusão no serviço do AEE, identificando onde as políticas deveriam se entrelaçar, para que as redes de apoio sejam efetivas na continuidade e no cumprimento das metas de incluir a todos.

\section{Notas}

1. Trata-se de um imperativo "porque o Estado toma a inclusão como um princípio — que por ser assumido como autoexplicativo e por guardar em si mesmo as razões que o justifica como uma necessidade imperiosa — é bom para todos”. (LOPES, 2001, p. 291).

2. Essa professora coordena as Salas de Recursos e os serviços de AEE da rede pública estadual não só do município de Cidreira, mas de todas as 106 escolas vinculadas à rede estadual nos 25 municípios que compõem a $11^{\text {a }}$ Coordenadoria Regional de Educação. Cabe destacar que a rede estadual conta com 11 Salas de Recursos Multifuncionais na região.

3. As entrevistas foram concedidas mediante a assinatura de um termo de livre consentimento, bem como foram explicadas todas as etapas da pesquisa e que seus dados pessoais seriam protegidos.

4. O poder é positivo quando ele é produtivo e estratégico, ao gerir e controlar a vida da população, visando a maximização das potencialidades dos sujeitos, transformando em força de trabalho. É positivo, pois assim diminui a sua capacidade de revolta contra as ordens estabelecidas e contribui para a eficácia da regulação (FOUCAULT, 2009a).

5. Empregamos esse termo para fazer alusão ao conceito de governamentalidade, cunhado por Foucault, que afirma que nossa realidade é inventada por discursos produzidos em movimentos biopolíticos que têm como alvo a população.

6. As entrevistas foram concedidas mediante a assinatura de um Termo de Livre Consentimento, bem como foram explicadas todas as etapas da pesquisa, garantindo que os dados pessoais seriam protegidos.

7. Será utilizado o itálico, no corpo do texto, nas falas dos participantes, como forma de diferenciação de outras citações.

8. Centro de Atenção ao Educando.

9. Conselho Tutelar 


\section{Referências}

BRASIL. Política Nacional de educação especial na perspectiva da educação inclusiva. Brasília: MEC/SEESP, 2008.

CANGUILHEM, G. O normal e o patológico. 5. ed. Rio de Janeiro: Forense Universitária, 2002.

CARVALHO, M. A.; PAIVA, G. M. A genealogia do poder em Foucault: as práticas discursivas e a sociedade disciplinar. Prisma Jurídico, v. 10, n. 1, p. 93-110, 2011.

CASTEL, R. A dinâmica dos processos de marginalização: da vulnerabilidade à desfiliação. Caderno CRH, v. 10, n. 26, p. 19-40, 1997.

COSTA, M. A.; MARGUTI, B. O. E. Atlas da vulnerabilidade social nos municípios brasileiros. Brasília: IPEA, 2015.

FAÉ, R. A genealogia em Foucault. Psicologia em estudo, v. 9, n. 3, p. 409-416, 2004.

FIMYAR, O. Governamentalidade como ferramenta conceitual na pesquisa de políticas educacionais. Educação \& Realidade, v. 34, n. 2, p. 35-56, 2009.

FOUCAULT, M. A verdade e as formas jurídicas. Tradução Roberto Machado; Eduardo Jardim Morais. Rio de Janeiro: EDIPUCRJ, 1974.

Vigiar e punir. Petrópolis: Vozes, 1975

História da sexualidade, 1: a vontade de saber. Rio de Janeiro: Graal, 1988.

. Aula de 17 de março de 1976. In: FOUCAULT, M. (Ed.). Em defesa da sociedade. São Paulo: Martins Fontes, 2002. p. 285-315.

. O uso dos prazeres e as técnicas de si. In: MOTTA, M. B. DE (Ed.). Michel Foucault: ética, sexualidade, política. Ditos \& Escritos. Rio de Janeiro: Forense Universitária, 2004. p. 192-217.

Nascimento da biopolítica. Tradução Eduardo Brandão. São Paulo: Martins Fontes, 2008a.

Os anormais. Tradução Eduardo Brandão. São Paulo: Martins Fontes, 2008b.

Segurança, território, população. Tradução Eduardo Brandão. São Paulo: Martins Fontes, 2008c.

A governamentalidade. In: MACHADO, R. (Ed.). Microfísica do poder. Curso do Collège de France, 01 de fevereiro de 1978. Tradução Roberto Machado. Rio de Janeiro: Graal, 2009a.

Genealogia e poder. In: MACHADO, R. (Ed.). Microfísica do poder. Curso do Collège de France, 1 de fevereiro de 1978. Tradução Roberto Machado. Rio de Janeiro: Graal, 2009b. p. 166-177.

. O nascimento da medicina social. In: MACHADO, R. (Ed.). Microfísica do Poder. Curso do Collège de France, 01 de fevereiro de 1978. Tradução Roberto Machado. Rio de Janeiro: Graal, 2009c. p. 95-132.

Poder-corpo. In: MACHADO, R. (Ed.). Microfísica do poder. Curso do Collège de France, 1 de fevereiro de 1978. Tradução Roberto Machado. Rio de Janeiro: Graal, 2009d. p. 145-152.

LOPES, M. C. Políticas de inclusão e governamentalidade. Educação \& Realidade, v. 34, n. 2, p. 153-169, 2009.

LOPES, M. C. Norma, inclusão e governamentalidade neoliberal. In: BRANCO, G. C. (Ed.). Foucault: filosofia \& política. Belo Horizonte: Autêntica, 2011. p. 283-298.

MENDES, E. G. Breve historia de la educación especial en Brasil. Revista Educación y pedagogia, v. 22, n. 57, p. 93-109, 2010.

SANTAIANA, R. DA S. + 1 ano é fundamental: práticas de governamento dos sujeitos infantis nos discursos do ensino fundamental de nove anos. Dissertação (Metrado em Educação) — Porto Alegre: Universidade Federal do Rio Grande do Sul, 2008. 
SARDAGNA, Helena V. Da institucionalização do anormal à inclusão escolar. In: FABRIS, E. H.; KLEIN, R. R. (Eds.). Inclusão e Biopolítica. Belo Horizonte: Autêntica, 2013. p. 45-60.

SKLIAR, C. Pedagogia (improvável) da diferença: e se o outro não estivesse aí? Tradução Giane Lessa. Rio de Janeiro: DP\&A, 2003.

VEIGA-NETO, A. Governo ou governamento. Currículo sem Fronteiras, v. 5, n. 2, p. 79-85, 2005.

\section{Correspondência}

Liziane da Silva Barbosa: Mestra em Educação pela Universidade Estadual do Rio Grande do Sul (UERGS); Professora da Rede Pública Estadual e Municipal de Cidreira-RS; Professora convidada do Curso de Graduação em Pedagogia da Universidade Estadual do Rio Grande do Sul (UERGS). Membro do Grupo de Pesquisa Educação e Processos Inclusivos (GPEPI).

E-mail: barbosalizzi@gmail.com

Helena Venites Sardagna: Doutora em Educação. Estágio pós-doutoral em Educação pela Universidade Federal do Rio Grande do Sul; Professora do Curso de Pedagogia e do Programa de Pós-Graduação em Educação da Universidade Estadual do Rio Grande do Sul (UERGS). Líder do Grupo de Pesquisa Educação e Processos Inclusivos (GPEPI).

E-mail: helena-sardagna@uergs.edu.br

Texto publicado em Currículo sem Fronteiras com autorização das autoras 